\title{
Comparative study between CFL and LED phototherapy devices for unconjugated hyperbilirubinemia in neonates
}

\author{
Khunte M. ${ }^{1}$, Panigrahi $D^{2}$, Kosam A. ${ }^{3}$ \\ ${ }^{1}$ Dr. M. Khunte, Assistant Professor, ${ }^{2}$ Dr. Deepak Panigrahi, Senior Resident, ${ }^{3}$ Dr. Ajay Kosam, Professor, all authors are \\ affiliated with Department of Paediatrics, Bharat Ratna Late Shri Atal Bihari Vajpayee Memorial Government Medical \\ College, Rajnandgaon, Chhattisgarh, India.
}

Corresponding Author: Dr. Deepak Panigrahi, F-6 Hospital Colony, Basantpur, Rajnandgaon, Chhattisgarh (C.G.) India. E-mail: drdeepak085@gmail.com

\begin{abstract}
Background: Neonatal hyperbillirubinemia is a common condition encountered in newborn. Phototherapy is a non invasive, cheap and safe modality for treatment of neonatal jaundice. Halogen spot light, fluorescent lamp devices, fiberoptic pads, compact fluorescent tubes and light emitting diodes are the various light sources used in phototherapy devices. This study was conducted to compare the efficacyof LED phototherapy with compact fluorescent light (CFL) phototherapy in management of healthy term and late preterm neonates with non-haemolytic jaundice. Methods: A randomized control study was conducted on 276 neonates of gestational age $>35$ weeks with significant hyperbilirubinemia. Patients were randomly allocated to CFL phototherapy group $(\mathrm{n}=147)$ and LED phototherapy group $(\mathrm{n}=129)$. Total serum bilirubin level at $12 \& 24$ hours, rate of fall of serum bilirubin, side effect profile, rebound hyperbilirubinemia and phototherapy failure was assessed. Result: Mean total bilirubin at 12 hours for LED and CFL phototherapy groups was comparable ( $\mathrm{p}>0.05$ ). Mean total serum bilirubin at 24 hours for LED phototherapy group was significantly lower as compared to CFL phototherapy group $(\mathrm{p}<0.05)$. Mean rate of fall of serum bilirubin was significantly higher in LED group as compared to CFL phototherapy group $(\mathrm{p}<0.05)$ but the mean duration of hospital stay was similar between two groups $(p>0.05)$. Side effect profile was comparable between two groups. Conclusion: LED phototherapy is superior to CFL phototherapy for management of neonatal hyperbilirubinemia. LED phototherapy has advantage of greater reduction in total serum bilirubin level and higher rate of fall of serum bilirubin as compared to CFL phototherapy. Both LED and CFL phototherapy has good safety profile.
\end{abstract}

Keywords: Compact fluorescent light, hyperbilirubinemia, light emitting diodes, mean total serum bilirubin, phototherapy.

\section{Introduction}

Neonatal hyperbilirubinemia is one of the common conditions encountered in day to day practice. The most dreaded complication of neonatal jaundice is kernicterus which is due to deposition of bilirubin in the brain causing yellowish discoloration of the brain, leading to bilirubin encephalopathy [1].

The level of bilirubin likely to result in neurotoxicity in neonate varies. Itdepends on multiple factors like acidosis, gestational age, postnatal age, rate of rise of serum bilirubin, serum albumin concentration, and concurrent illness [2]. There are many modalities available in the treatment of neonatal jaundice.

Manuscript received: $4^{\text {th }}$ February 2019

Reviewed: $10^{\text {th }}$ February 2019

Author Corrected: $15^{\text {th }}$ February 2019

Accepted for Publication: $19^{\text {th }}$ February 2019
Among them the time tested ones are exchange transfusion and phototherapy. Phototherapy being noninvasive, cheap, safe and with fewer side effects have become the treatment of choice for the management of neonatal jaundice worldwide [3]. Phototherapy causes conversion of bilirubin levels into water soluble isomers which are excreted in urine through photo-oxidation, configurational isomerisation and structural isomerisation.

Phototherapy uses light in range of blue-green spectrum (400-520 nm). The sources of light for phototherapy are halogen spot light, fluorescent lamp devices, fiberoptic pads, compact fluorescent tubes and the latest ones light emitting diodes. The problems with the initial light sources were they were large, produced excessive heat 
and with poorer irradiance levels and requirement of frequent replacement of the tubes or bulbs [4]. Among the light sources mentioned above the most commonly sources used worldwide now days are conventional compact fluorescent light units followed by which newly developed light emitting diode phototherapy units.

Compact fluorescent light units are less space occupying had higher irradiances and have lower power consumption compared to older units. The problem of significant heat production was still pertaining along with emission of unstable broad wavelength, requirement of frequent assessment of irradiance and timely change of the light units $[5,6]$.

LED phototherapy units which were developed in late 90's by incorporating gallium nitrite light emitting diodes proved to be giving higher irradiance with cheaper cost, less heat production, extended life span, narrow spectrum wavelength, duration of change of bulbs nearly 20,000 hours compared to 2000 hours of conventional fluorescent lights. In theory these lights are far superior to conventional phototherapy units [7].

Since the incorporation of LED phototherapy units in the management of neonatal jaundice large number of studies have been done worldwide comparing the efficacies with different light sources.

But only few published studies are available from India comparing compact fluorescent light units with LEDs [8].

We conducted this study to answer the question "whether LED phototherapy is as efficacious or is better as the standard compact fluorescent light (CFL) phototherapy in management of healthy term and late preterm neonates with non-haemolytic jaundice.

\section{Aim}

To compare the efficacy of LED \& CFL phototherapy devices

\section{Objectives}

1) To compare initial 12 hour and 24 hour bilirubin levels in two groups receiving LED and CFL phototherapy after start of therapy.

2) To compare rate of fall of bilirubin in two groups receiving CFL \& LED phototherapy

3) To compare side effect profile of both the devices.

\section{Material and Methods}

Source of data- During the study, a total of 276 neonates, admitted in the SNCU of Bharat Ratna Late Shri Atal Bihari Vajpayee Memorial Government Medical College, Rajnandgaon (C.G.) with significant neonatal jaundice requiring phototherapy were enrolled in the study. The study was approved by institutional ethics committee. Written informed consent was obtained from the parents on format before evaluating the patient.

Study period- December 2017 to November 2018

Sample size-276 (calculated from Epi, Version 3 open source calculator)

Sample size determination- Sample size was estimated using the formula as recommended by Fisher [9] $\mathrm{n}=\mathrm{z}^{2} \mathrm{pq} / \mathrm{d}^{2}$

Study design- The present study is randomized control study.

Inclusion criteria- All neonates of gestational age more than 35 weeks admitted to neonatal intensive care unit with significant hyperbilirubinemia.

\section{Exclusion criteria}

1. Neonates with physiological hyperbilirubinemia.

2. Neonates with gestational age less than 35 weeks

3. Neonates with major congenital malformation i.e, gastrointestinal, syndromic neonates, cardiovascular anomalies.

4. Culture positive or clinical sepsis.

Methodology- As per protocol all neonates were monitored in natural light for appearance of jaundice clinically. A blood sample for total serum bilirubin (TSB) and conjugated serum bilirubin was obtained if jaundice was evident $<24$ hours of age, or neonate was icteric till the abdomen based on Kramer's rule [10] clinically. Doumas reference method (modified Jendrassik and Grof procedure) was used for estimation of total and conjugated bilirubin in neonates with bilirubin levels greater than or equal to grade 3 by Kramer's rule clinically.

Whole blood was taken in micro-capillary and centrifuged at the rate of $3000 \mathrm{rpm}$ for 5 minutes. Bilirubin estimation was done spectro photo metrically using the wave length (530-560nm) and bichromatic 


\section{Original Research Article}

wavelength used is $540 \mathrm{~nm}$, by automatic analyze. Phototherapy was started as per guidelines by American Academy of Paediatrics [11]. Gestational age was determined based on last menstrual period and New Ballard score [12].

Neonates with jaundice requiring phototherapy fulfilling the inclusion criteria were taken for study. Neonates were randomly allocated to receive LED or CFL phototherapy using sealed envelope prepared from random number table.

Basic anthropometric measurements like weight and length were taken at the time of admission \& informed consent was obtained from parent on format before evaluating each patient. A detailed history with respect to the onset of jaundice, risk factors present, maternal drugs (oxytocin, diazepam, promethazine), maternal risk factors (age $>24$ years, diabetes, order of gestation, oral contraceptive use at time of conception), previous sibling history, feeding history, starting of phototherapy.

All neonates were examined for bruises, cephalhematoma, scalp injuries, liver and spleen enlargement. Following mandatory investigations were done in all babies: hematocrit, peripheral smear, reticulocyte count, total and conjugated bilirubin, blood group of mother and baby and direct Coomb's test. TSH level and septic screen was done whenever applicable.

The phototherapy devices used were MEDI WAVES Inc. CFL phototherapy units. LED units used were PHOENIX LED PT 100 phototherapy units with blue LEDs as illumination source, peak spectral irradiance of the device being $50 \mathrm{microW} / \mathrm{cm}^{2} / \mathrm{nm}$ at a distance of 45 $\mathrm{cm}$ from the light source, peak wavelength $451 \mathrm{~nm}$, and emitted spectrum in the range of 430-490 nm.
The patients were placed in supine position and fully exposed to light except for diaper and eye region. A distance of $35 \mathrm{~cm}$ was maintained between the patient and the light source. Spectral irradiance was measured 6 monthly till the completion of therapy.

Spectral irradiance was measured using Phoenix spectro radiometer by placing irradiance meter on the centre of the infant bed. Phototherapy was discontinued when bilirubin was $<12 \mathrm{mg} / \mathrm{dl}$ in term and $<8 \mathrm{mg} / \mathrm{dl}$ in preterm.

Total serum bilirubin was estimated at the time of admission, then at 12 hours of therapy and then at 24 hours of therapy. The duration of phototherapy was calculated by subtracting age at start of phototherapy from age at end of phototherapy in days.

Rate of fall of total serum bilirubin was calculated by subtracting total serum bilirubin at the end of phototherapy from total serum bilirubin at the start of therapy and dividing this value by 24 , this gave rate of fall in $\mathrm{mg} / \mathrm{dl} / \mathrm{hr}$.

Side effects were monitored like skin rashes, temperature instability, hypothermia $\left(<36.5^{\circ} \mathrm{C}\right)$ or hyperthermia $\left(>37.5^{\circ} \mathrm{C}\right)$. Failure of phototherapy was defined as total serum bilirubin level becoming more than $20 \mathrm{mg} / \mathrm{dl}$ during phototherapy. Rebound hyperbillirubinemia was defined as rise in total serum bilirubin levels to significant value anytime after discontinuation of phototherapy.

Statistical analysis- Results are expressed as mean \& SD. Numerical data were analyzed by SPSS 21.0 Version. Continuous data with normal distribution was analysed by student t-test, and categorical data was analysed using chi-square test.

\section{Results}

Table-1: Demographic data.

\begin{tabular}{|c|c|c|c|}
\hline Demographic parameters & CFL group $(n=147)$ & LED group $(n=129)$ & P value \\
\hline Birth Weight $(\mathrm{Kg})($ mean \pm SD $)$ & $2.59 \pm 0.43$ & $2.57 \pm 0.51$ & \multirow{4}{*}{$\begin{array}{c}\mathrm{P}>0.05 \text { not } \\
\text { significant }\end{array}$} \\
\hline Male & $87(59 \%)$ & $73(57 \%)$ & \\
\hline Female & $60(41 \%)$ & $56(43 \%)$ & \\
\hline Gestational Age (weeks) & $37.65 \pm 0.785$ & $37.75 \pm 0.709$ & \\
\hline Mean TSB on admission (mg/dl) & $17.587 \pm 2.54$ & $16.58 \pm 2.13$ & $\mathrm{P}<0.05$ significant \\
\hline
\end{tabular}

In our study, the demographic data of the two groups were comparable in terms of birth weight, sex and gestational age ( $p>0.05$ ) but the mean total serum bilirubin level on admission was significantly higher in CFL group as compared to LED group (Table 1). 
Table-2: Mean total serum bilirubin at 12 hours \& 24 hours.

\begin{tabular}{|l|c|c|c|}
\hline & CFL group & LED group & P value \\
\hline Mean total serum bilirubin at 12 hour $(\mathrm{mg} / \mathrm{dl})$ & $13.62 \pm 2.417$ & $13.89 \pm 2.416$ & $\begin{array}{c}\mathrm{P}>0.05 \\
\text { Not significant }\end{array}$ \\
\hline Mean total serum bilirubin at 24 hour $(\mathrm{mg} / \mathrm{dl})$ & $10.85 \pm 2.53$ & $10.32 \pm 2.25$ & $\begin{array}{c}\mathrm{P}<0.05 \\
\text { Significant }\end{array}$ \\
\hline
\end{tabular}

In our study the mean total serum bilirubin at 12 hours for LED and CFL groups $\mathrm{mg} / \mathrm{dl}( \pm \mathrm{SD})$ are $13.89( \pm 2.416) \mathrm{mg} / \mathrm{dl}$ \&13.62 $( \pm 2.417) \mathrm{mg} / \mathrm{dl}$ respectively \& the difference between two groups is statistically not significant $(\mathrm{p}>0.05)$

In our study mean total serum bilirubin at 24 hours mg/dl (+/-SD) in LED \& CFL groups are 10.32( \pm 2.25$) \mathrm{mg} / \mathrm{dl} \&$ $10.85( \pm 2.53) \mathrm{mg} / \mathrm{dl}$ respectively \& the difference between two groups is significant $(\mathrm{p}<0.05)$

Table-3: Rate of fall of serum bilirubin.

\begin{tabular}{|l|c|c|c|}
\hline & CFL group & LED group & P value \\
\hline Mean rate of fall of TSB $(\mathrm{mg} / \mathrm{dl} / \mathrm{hr})$ & $0.23 \pm 0.06$ & $0.302 \pm 0.04$ & $\mathrm{P}<0.05$ \\
& & & Significant \\
\hline
\end{tabular}

In our study mean rate of fall of serum bilirubin $-\mathrm{mg} / \mathrm{dl} / \mathrm{hr}( \pm \mathrm{SD})$ in both the groups are $0.302( \pm 0.04) \mathrm{mg} / \mathrm{dl} / \mathrm{hr} \&$ $0.23( \pm 0.06) \mathrm{mg} / \mathrm{dl} / \mathrm{hr}$ for LED \& CFL respectively \& the mean rate of fall of serum bilirubin is significantly higher in LED group $(\mathrm{p}<0.05)$

Table-4: Mean duration of hospital stay.

\begin{tabular}{|l|c|c|c|}
\hline & CFL group & LED group & P value \\
\hline Mean duration of hospital stay (days) & $2.77 \pm 0.88$ & $2.69 \pm 1.2$ & $\begin{array}{c}\text { P }>0.05 \\
\text { Not significant }\end{array}$ \\
\hline
\end{tabular}

In our study mean duration of stay (days) $( \pm \mathrm{SD})$ in both the groups are $2.69( \pm 1.2)$ days \& $2.77( \pm 0.88)$ days for LED \& CFL group respectively which was statistically not significant.

Table-5: Side effect profile-LED \& CFL devices.

\begin{tabular}{|c|c|c|c|}
\hline Side Effects & CFL group & LED Group & \multirow{2}{*}{ P value } \\
\hline Hyperthermia & 0 & 0 & \multirow{2}{*}{ Not Significant } \\
\hline Hypothermia & 8 & 7 & \\
\hline Rebound hyperbillirubinemia & 5 & 4 & \\
\hline Skin rashes & 2 & 115 & \\
\hline Nil & 132 & 3 & \\
\hline
\end{tabular}

In our study 7 cases had hypothermia, 4 cases had rebound hyperbillirubinemia \& 3 cases had skin rashes in LED group $\&$ in CFL group there were 8 cases of hypothermia, 4 cases of rebound hyperbillirubinemia \& 2 cases of skin rashes and there was no significant difference between the side effect profiles of two groups; $(\mathrm{p}>0.05)$.

\section{Discussion}

Phototherapy is the most widely used modality to treat neonatal hyperbilirubinemia. Response to phototherapy depends on several factors like efficacy of the phototherapy device and balance between rate of bilirubin production and elimination [13]. The efficacy of phototherapy depends on characteristics of the light source such as emission peak wavelength, emission range and irradiance [14].
There is no 'standard' recommended method of providing phototherapy. Different researchers follow a variety of strategies. This study was done to see if LED phototherapy devices have better efficacy and fewer side effects. Mean total serum bilirubin at 12 hours of initiation of therapy for LED and for CFL group was comparable in our study. Similar observation was noted by other researchers who found insignificant difference 
in mean serum bilirubin 4 to 15 hours after start of therapy between LED and CFL phototherapy group $[5,14]$. In our study mean total serum bilirubin at 24 hours of initiation of therapy was significantly lower in LED phototherapy group as compared to CFL phototherapy group.

Similar to our study Martins et al \& Rattakhet et alobserved that 24 hour mean TSB was lower in LED phototherapy group than CFL group $[15,16]$. Karagol etal in his study found no significant difference in 24 mean TSB between LED and CFL group which was contradictory to our study [17].

Mean rate of fall of serum bilirubin was significantly higher in LED group in our study. Similar findings were observed by studies done by Karagol et al and Reddy et alwhere the rate of fall of TSB was significantly higher for LED group [17, 18]. Contrary to our study several other studies however reported that the rate of fall of TSB was comparable between two groups [6, 19].

In our study mean duration of hospital stay was similar between LED \& CFL phototherapy group. The duration of hospital stay was reported in other study in which there was no significant difference between two groups similar to our study $[5,6$,$] .$

Significant decrease in duration of phototherapy in the LED group unlike our study was reported by Martins et al and Karagol et al. This may be because of use of a specific type of LED phototherapy, with a different physical and chemical composition (indium gallium nitrate) $[15,17]$.

In our study hypothermia, rebound hyperbillirubinemia and skin rashes were observed as phototherapy side effects but these were comparable in LED and CFL phototherapy group.

Hypothermia was rare in the two groups. Some studies comparing adverse effect profile reported complete absence of temperature instability and skin rash in both the study groups $[14,15]$. Significantly higher number of rebound hyperbilliru-binemia was noted in study conducted by Karagolet al[17].

Treatment failure, defined as need for additional phototherapy or exchange transfusion, was reported in studies by Kumaret al [14] and Martins et al [15].

However the number of treatment failure cases was very small. In our study treatment failure was not reported.

\section{Conclusion}

LED phototherapy units are better than CFL phototherapy units for management of neonatal jaundice in terms of rate of fall of serum bilirubin. LED devices are more efficient in bringing down serum bilirubin level to lower levels in a particular duration of time compared to CFL devices. However these devices do not alter the duration of stay of the neonates. Both devices have fewer \& similar side effect profile.

Funding: Nil, Conflict of interest: None initiated, Perission from IRB: Yes

\section{References}

1. Porter ML, Dennis BL. Hyperbillirubinemia in the term newborn. Am Fam Physician. 2002 Feb 15; 65(4): 599-606.

2. Watchko JF, Tiribelli C. Bilirubin-Induced Neurologic Damage- Mechanisms and Management approaches. N Eng J Med. 2013 Nov; 369: 2021-2030.

3. Tan KL, Lim GC, Boey KW. Efficacy of "high intensity" blue-light and "standard" daylight phototherapy for non-haemolytic hyperbillirubinemia. Acta Paediatr. 1992 Nov; 81(11):870-4.

4. Subramanian S et al. Evaluation of phototherapy devices used for neonatal hyperbillirubinemia. Indian Pediatr. 2011 Sep;48(9):689-96.Epub2010Nov 30.

5. Maisels MJ, Kring EA, DeRidder J. Randomized controlled trial of light-emitting diode phototherapy. J Perinatol. 2007 Sep;27(9):565-7. Epub 2007 Jun28.

6. Seidman DS, Moise J, Ergaz Z, Laor A, Vreman HJ, Stevenson DK et al. A new blue light-emitting phototherapy device: A prospective randomized controlled study. J Pediatr. 2000 Jun; 136(6):771-4

7. Vreman HJ, Wong RJ, Stevenson DK, Route RK, Reader SD, Fejer MM, Gale R \& Seidman DS. LightEmitting Diodes: A novel light source for phototherapy. Pediatr Res.1998 Nov; 44(5): 804-9.

8. Agarwal R, Kaushal M, Aggarwal R, Paul VK, Deorari AK.Early neonatal hyperbillirubinemia using first day serum bilirubin level. Indian Pediatr.2002 Aug; 39(8):724-730.

9. Charan J, Biswas T. How to calculate sample size for different study designs in medical research? Indian J Psychol Med. 2013 Apr-Jun; 35(2): 121-26. 


\section{Original Research Article}

10. Wan ASL, Mat Daud S, Teh SH, Choo YM, Kutty FM. Management of neonatal jaundice in primary care. Malays Fam Physician. 2016; 11 (2 \& 3): 16-19.

11.American Academy of Pediatrics Subcommittee on Hyperbillirubinemia. Management of hyperbillirubinemia in the newborn infant 35 or more weeks of gestation. Pediatrics.2004 Jul; 114(1) :297-316.

12. Ballard JL, Khoury JC, Wedig K, Wang L, EilersWalsman BL, Lipp R. New Ballard Score expanded to include extremely premature infants. J Pediatr. 1991 Sep; 119 (3): 417-23.

13. Vinod K. Bhutani, the Committee on Fetus and Newborn. Phototherapy to prevent Severe Neonatal Hyperbilirubinemia in the Newborn Infant 35 or more Weeks of Gestation.Pediatrics2011 Oct; 128 (4): e1046.

14. Kumar P, Chawla D, Deorari A. Light-emitting diode phototherapy for unconjugated hyperbilirubinemia in neonates. Cochrane Database of Syst Rev. 2011 Dec 7; (12):CD007969. doi: 10.1002/ 14651858. CD007969.pub2.

15. Martins BM, de Carvalho M, Moreira ME, Lopes JM. Efficacy of new micro processed phototherapy system with five high intensity light emitting diodes
(Super LED). J Pediatr (RioJ) 2007 May-Jun; 83 (3): 253-8.

16. Ratthakhet E., Rattikarn Maneenut RN, Jiraporn Kardreunkaew RN, Waleerat Khobkhun RN, Sunaree Saenphrom RN. The Efficacy of the In-House LightEmitting Diode Phototherapy Equipment Compare to Conventional Phototherapy Equipment on the Treatment of Neonatal Hyperbillirubinemia. J Med Assoc Thai 2013; 96 (12): 1536-41.

17. Karagöl BS, Erdeve O, Atasay B, Arsan S. Efficacy Of Light Emitting Diode phototherapy in comparison to conventional phototherapy in neonatal jaundice. Journal of Ankara University Faculty of Medicine 2007; 60 (1): 31- 34.

18. Reddy TR, Prasad PK, Parakh H, Nagar P. Lightemitting Diodes versus Compact Fluorescent Tubes for Phototherapy in Neonatal Jaundice: A randomised control trial. Pediatr Rev: Int J Pediatr Res 2014; 1(3): 67-74. doi: 10.17511/ijpr.2014.3.003.

19. Seidman DS, Moise J, Ergaz Z, Laor A, Vreman HJ, Stevenson DK, et al. A prospective randomized controlled study of phototherapy using blue and bluegreen light-emitting devices, and conventional halogenquartz phototherapy. J Perinatol.2003 Mar;23(2):123-7.

\section{How to cite this article?}

Khunte M, Panigrahi D, Kosam A. Comparative study between CFL and LED phototherapy devices for unconjugated hyperbilirubinemia in neonates. Int J Pediatr Res. 2019;6(02):70-75. doi:10.17511/ijpr.2019.i02.04 